\title{
湘中保和堂煤的特 征*
}

\section{钟建华 王文祥 王钟秀 易改危}

(湖泟矿业学院地质系, 湘潭 411201)

关謟调和堂、腐泥基质、渗出励青体

一、概述

保和堂矿区位于湖南省中部的邵东县境内. 区内的含煤地层为龙潭组, 厚约 $200 \mathrm{~m}$, 含煤 四层, 下部两层一般不可采, 上部两层为可采煤层, 分别均厚 0.60 和 $1.19 \mathrm{~m}$, 其元素组成及工 艺参数等见表 1 . 由表 1 可以看出, 保和堂煤(以下简称保煤)为一种低灰、特低硫、特低磷、富 油及高发热量的优质煤. 其煤岩及热解性质较独特.

表 1 保煤的元萦组成及工艺性质等参数

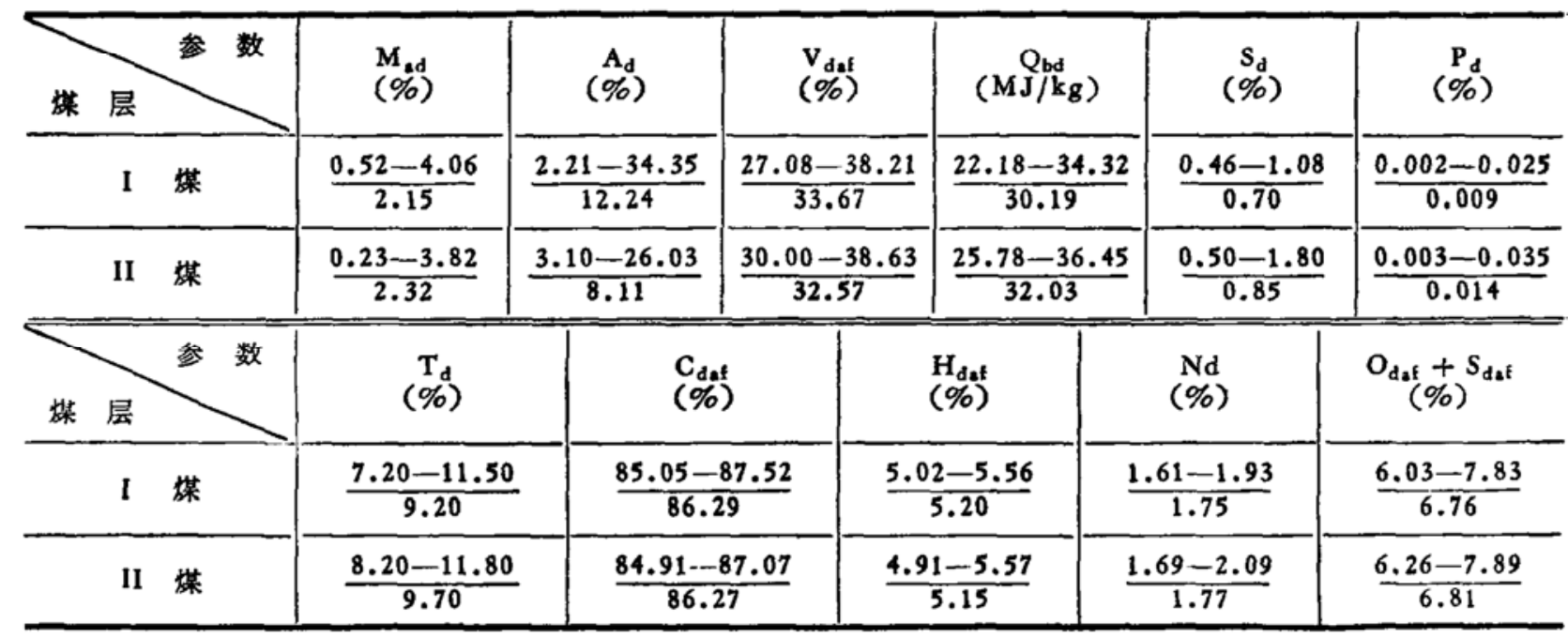

\section{二、保煤的特点}

1. 媒岩特点对保煤进行了详细的煤岩学研究, 发现其煤岩特点较突出, 表现在:

（1）显微组成主要讨论有机组分. 表 2 是保煤的有机显微组成, 由此可知其主要特 点是, 镜质组相对较少, 而过渡组和腐泥基质相对较多; 稳定组以腐泥基质和小孢子体为主.

（2）腐泥基质 含量丰富(见表 2). 多呈团块状、条带状或不定形状. 油漫反射光下 为黑灰色, 表面均一或呈基质状. 有必要指出的是, 在保煤中发现了一种具有一定形态和结构 的腐泥状物, 其主要特征是, 丝发状腐泥围绕一腐泥核呈放射状排列, 彼此相交或不相交, 其末 端常膨大成小球状, 见图 1. 作者将其称为放射状腐泥体, 推测其可能是一种浮游生物的“遗 体”, 进而推测煤中的腐泥基质可能是由这种“浮游生物”所形成的, 因为在煤中未发现任何藻

本文 1990 年 1 月 18 日收到.

* 煤族科学基金资助课题. 
表 2 保煤的有机显微组成*

\begin{tabular}{|c|c|c|c|c|c|c|c|c|c|}
\hline \multirow[b]{2}{*}{ 碟层 } & \multirow{2}{*}{ 显微组成 } & \multirow{2}{*}{$\begin{array}{l}\text { 有机组分 } \\
\therefore(\%)\end{array}$} & \multicolumn{2}{|c|}{$\mathbf{J}$} & \multirow{2}{*}{$\begin{array}{l}\text { BJ } \\
(\%)\end{array}$} & \multirow{2}{*}{$\begin{array}{l}\text { BS } \\
(\%)\end{array}$} & \multirow{2}{*}{$\stackrel{s}{(\%)}$} & \multirow{2}{*}{$\begin{array}{l}F_{\mathrm{n}} \\
(\%)\end{array}$} & \multirow{2}{*}{$\begin{array}{l}\mathrm{w}_{\mathrm{b}} \\
(\%)\end{array}$} \\
\hline & & & $\mathrm{ji}(\%)$ & $j w(\%)$ & & & & & \\
\hline & I & $88-95$ & $5-12$ & $25-37$ & $13-20$ & $15-20$ & $15-28$ & $10-18$ & $5--11$ \\
\hline & Il & $86-94$ & $7-20$ & $24-32$ & $15-22$ & $10-27$ & $10-24$ & $12-21$ & $7-10$ \\
\hline
\end{tabular}

* $\mathrm{F}_{\mathrm{a}}$ 一一属泥基质; $\mathrm{W}_{\mathrm{b}}$ 一一主要为小孢子体; 资出伍青体未计算在内.

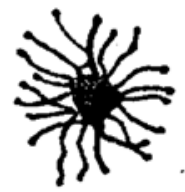

图 1 放射状腐泥体 $\times 120$

类体.还发现，腐泥基质与黄铁矿呈正相关关系，表明其成因与黄铁矿的成因可能有关.

（3）渗出沥青体十分常见, 多充填在裂隙或孔隙中, 呈流动状态(常使煤砖光片油迹 斑斑). 图 2 是充填在孔隙中的渗出沥青体, 光照后由孔隙内向外扩散，在孔隙四周形成油膜. 据资料, 渗出汸青体仅见于腐植煤中, 其成因仅与由高等植物形成的富氢镜质体和稳定组有 关, 而腐泥煤中则无渗出饬青体 ${ }^{[1]}$. 但作者认为, 保煤中的渗出伍青体主要是由腐泥基质形成 的, 其成因有待进一步探讨. 在以往的钻探中经常发现砂岩中有液态烃, 作者也在野外砂岩中 发现多处有油迹(如在德新堂附近, 龙潭组最底部的厚层状砂岩中便有油迹). 作者认为,煤系 中的液态烃是煤中的渗出伍青体迁移之故。

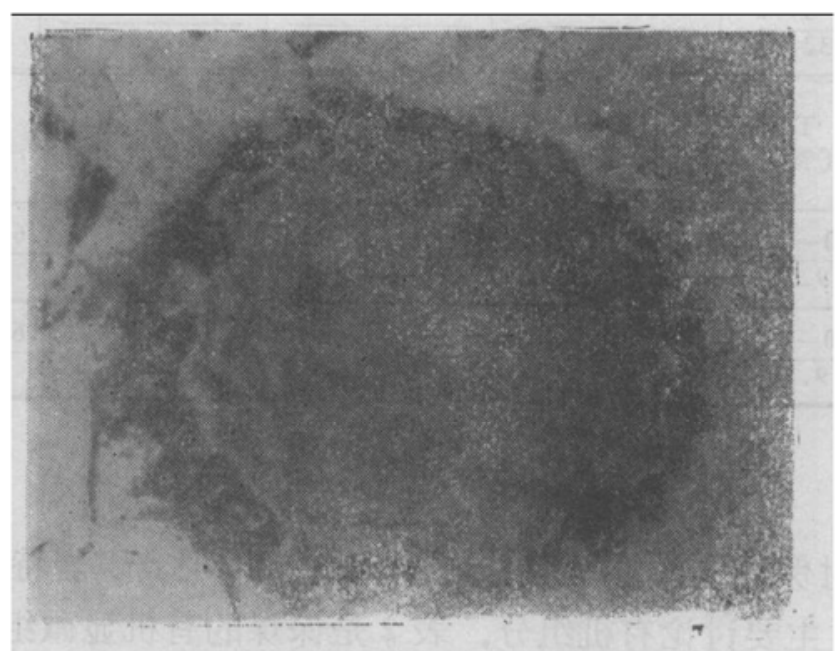

图 2 孔隙中的渗出励青体, 油漫 $\times 120$

（4）微粒体 保煤的另一个重要特点是含有大量微粒体, 其大小多在数微米左右, 较一 般微粒体大(微粒体通常多在 1 微米左右或小于 1 微米), 多集合成条带状、不规则片状或细丝 状产于镜质体中，或细分散状产出．其成因可能与镜质体有关，可能是富氢镜质体泊青化作 用的产物,但不能排除原生成因,值得研究.

\section{2. 热解特征 对保煤进行了热解分析,结果见表 3 .}

从表 3 可以看出,保煤的热解特点如下:

(1) $S_{2}$ 经对比,保煤的 $S_{2}$ 高于某些同煤级煤 1 至数倍. 
表 3 保煤的热解分析结果

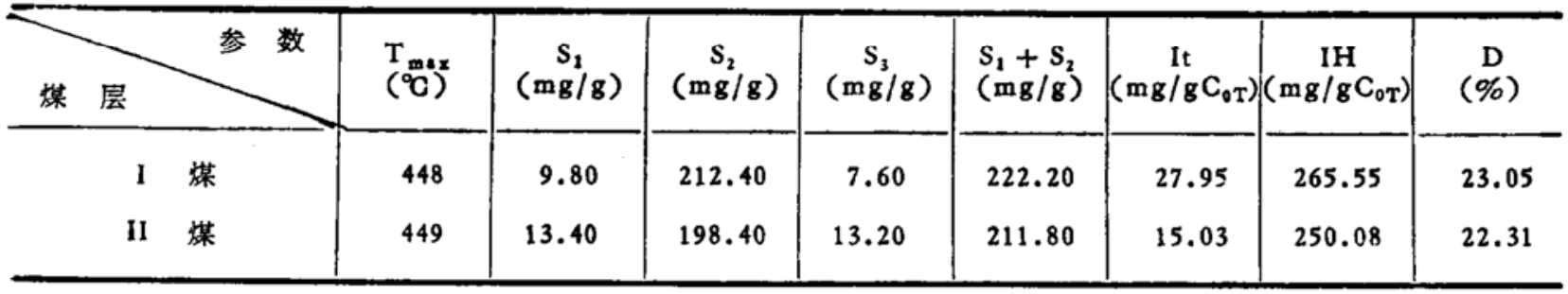

（2）It 由此看,保和堂的 I 煤在生油上具有 I 型干酪根的特点 ${ }^{[2]}$, 具有很强的生油能 力; 而 II 煤在生油上则具有 II 型干酪根的特点,具有较强的生油能力.

（3）IH 及 D 这两个参数都表明了保煤在生油上具有 II 型干酪根的特点, 具有较强 的生油能力.

总之, 从热解分析看来, 保煤具有较强的生油能力. 因此, 又有理由从另一个角度认为煤 系中的液态烃由煤所形成。

从煤岩学研究及热解分析结果可知, 保煤具有较大的特殊性, 对其进行深入研究具有一定 的意义。

致谢: 作者感谢中国科学院地质研究所完成样品的热解分析, 还应感谢湘潭矿业学院 MPV 3 实验室.

\section{参考文献}

[1] Robert, P., Intern. J. Coal Geol., 3(1981),2: 101-138.

[2] 邬立容等,生油岩热解快速定量评价,科学出版社, 1986, 27-30. 